\title{
INICIACION FEMENINA, PROCESO DE GESTACION, ALUMBRAMIENTO, ABORTO E INFANTICIDIO ENTRE LOS MATACO, TOBA Y PILAGA
}

\author{
Anatilde Idoyaga Molina \\ Centro Angentino de Etnología Americana, \\ Buenos Aires, Argentina.
}

\begin{abstract}
In this article the author describes the notions and practices related to conception, pregnancy, birth, abortion and infant killing found in three indigenous peoples of the Argentinian Chaco: the matacos, the tobas and the pilagás.
\end{abstract}

Los mataco pertenecen al grupo lingüístico mataco-maká, y los toba y pilagá al guaycurú. Se hallan asentados en el Chaco Argentino, en las provincias de Formosa, Chaco y Salta, a excepción de los pilagá que habitan en territorio formoseño. Si bien la situación de contacto es de larga data y ha originado cambios y adaptaciones, puede decirse que las cosmovisiones nativas mantienen vigencia y que es a partir de las mismas que se entienden las alteraciones producidas.

En esta oportunidad intentaremos acercarnos a las nociones y prácticas relativas a la iniciación femenina, la concepción, la gravidez, el alumbramiento, el aborto y el infanticidio, haciendo especial hincapié en las explicitaciones y sentidos que tienen para los propios indígenas. La similitud de numerosos aspectos en los tres grupos nos permite el tratamiento conjunto. 1

Los materiales sobre los que nos basamos provienen de numerosas campañas de investigación que realizamos personalmente, con el objeto primordial de efectuar una hermenéutica cultural.

\section{Iniciación femenina}

La iniciación femenina se efectúa indefectiblemente con la llegada de la menarca. Ella implica un encierro riguroso para la joven, que es aislada mediante mantas en una esquina de la choza. Allí pasa todo el tiempo hilando y trenzando lana y fibras vegetales para hacer textiles, vinchas, bolsas y otras manufacturas tradicionales. Las únicas salidas son de orden fisiológico y las realiza completamente cubierta y en compañía de una anciana. El ocultamiento, incluso del rostro, impide que sea divisada e identificada por los personajes míticos que merodean acechantes la vivienda con nefastas intenciones. La necesidad de escolta se explica por el poder que poseen los viejos, que neutraliza, en cierta medida, las posibilidades de daño.

Otro conjunto de observancias son de orden alimenticio. Le son interdictas las carnes, tanto de animales montaraces como de peces; sólo puede comer algunos vegetales recolectables en poca cantidad y beber agua discretamente, lo que equivale a decir que se somete a un ayuno riguroso.

Entre los toba y pilagá tampoco puede tocar armas de caza o útiles de pesca, puesto que el olor penetrante y negativo de la sangre menstrual los impregnaría espantando las posibles presas.

La prohibición más significativa es la que le impide acercarse a los esteros y lagunas, la morada de un ser mitológico, cuyo rasgo 
sobresaliente es la repugnancia que experimenta ante las mujeres en período, la que lo lleva a reacciones iracundas y violentas, como el envío de una gran tormenta que inunda y hace desaparecer la aldea. De tal acontecimiento da cuenta un episodio mítico -ejemplar a este respecto-2, y las referencias a casos concretos en el presente, sobre la reiteración de su actuar. Mirar el cielo y especialmente las nubes conlleva a un desenlace similar entre los guaycurú.

Finalmente, entre los pilagá, la choza es rodeada con ceniza a fin de prevenir acciones malevolentes de las deidades o del shamán. Cabe acotar que aquella, un derivado del fuego, integra el mismo dominio semántico y opera como protector y purificador.

El encierro culmina al concluir la segunda regla. En dicha ocasión la joven muestra el producto de su trabajo, el que precisa el paso de adolescente a mujer, a la vez que su aptitud para el matrimonio, lo que obviamente se materializa en el cambio de la clase de edad.

El ritual descripto, dominado por observancias y tabúes, pone en claro el carácter crítico de la iniciación, su condición de umbral y, por otra parte, la impureza de la sangre y de la joven menstruante, cuyo poder contaminante contagia y mancilla lo que toca, pero también la hace objeto de la disposición negativa de los seres poderosos. Es esa misma impureza la que nos permite comprender más profundamente la proscripción de aproximarse al agua, no ya como la mera imposición de un personaje, sino como la incompatibilidad de entidades que simbolizan realidades heterogéneas y excluyentes. El agua, el fuego, la ceniza, son regeneradores, restauradores de estados positivos: son expresión de lo puro. Como contrapartida, el fluído femenino y su olor fuerte y desagradable connotan la enfermedad, el peligro y aún, la proximidad de la muerte (Idoyaga Molina, 1988).

\section{Concepción}

Las ideas relativas a la concepción privilegian el papel masculino, en virtud de que son las sucesivas deposiciones seminales las que, por sí mismas, conforman el embrión -y la placenta entre los toba y pilagá-. La mujer es un mero receptáculo que no hace aporte biológico alguno. Lo dicho se expresa en el plano de la lengua, los mataco denominan a la placenta y al útero -cuyas funciones se confundenjanajwáj-ji (janajwáj: niño, ji: recipiente); usan también la voz lakají (se traduce como bolsa, la es un prefijo de tercera persona y el sufijo $j i$ denota siempre continencia). Por el contrario, el término o-lés significa, mi semilla (vegetal), mi esperma, mi hijo, es decir refiere su carácter fecundante y la identificación entre el semen y la procreación. (Idoyaga Molina, 1978/79, de los Ríos, 1974). De acuerdo con el indígena, la mujer guarda en su interior un número limitado de lakaji, el cual determina la cantidad de embarazos que pueda tener.

Entre los pilagá la expresión kogót logót kyé (lit. hijo, su, continente), que designa al útero, remarca el papel de reservorio ya mencionado. A diferencia de los mataco, no hay límite para las posibilidades de preñez, por los motivos señalados más arriba (Idoyaga Molina, 1976/77).

Para concretar la gestación es necesario que los padres copulen frecuentemente, de modo que se forme el embrión totalmente. La idea es que al principio se gesta un núcleo originario, el que se va desarrollando como resultado del contacto sexual copioso, y es así que van apareciendo los diferentes órganos, hasta la estructuración completa del feto. (Idoyaga Molina, 1966/77, 1978/79 y de los Ríos, 1974).

La esterilidad es siempre una falta femenina, y su explicación supera la esfera puramente fisiológica. Encuentra su fundamento en el actuar maléfico de los seres míticos, que dañan la anatomía de la joven implicando la acumulación del esperma. Ante esta circunstancia, lo habitual es recurrir al shamán que mediante el soplo y la succión retira la enfermedad-sustancia y facilita la gravidez (Idoyaga Molina, op. cit.).

Por otra parte, la capacidad generativa es una incorporación realizada en el tiempo míti$\mathrm{co}$, de la que da cuenta el difundido tema chaqueño sobre el origen de las mujeres. ${ }^{3}$ Es en esa ocasión que se introduce el coito con su modalidad actual, puesto que se quiebran los dientes vaginales, se inicia la erección peneana y se le otorga a la cópula su sentido, en tanto acto siempre e inmediatamente fecundante.

Otros aspectos evidencian que la etnofisiología integra contenidos de índole diversa: 
social, religiosa, etc. Así, el verdadero cimiento del crecimiento embrionario reposa en la presencia de la entidad anímica, la que define cabalmente la humanidad del ser en gestación, y se percibe en los movimientos, la intencionalidad de nacer y todo aquello que sea alusión a vida.

El padre por ser el "hacedor" del vástago es su dueño y éste su dependiente, modelo de nexos que reproduce los que organizan la sociedad y el cosmos y que devela la peculiaridad de la relación, en términos jerárquicos y de poder. $\mathrm{Al}$ padre le corresponde la socialización, manutención y endoaculturación de los hijos, lo que indica que de él depende la existencia de los últimos (Idoyaga Molina, 1976/77 y $78 / 79$ ).

El factor efectivo y la libertad, respecto del deseo de asumir o no ese rol hace que entre los pilagá, quienes no sólo conocen la paternidad biológica sino que la exageran, aparezca el fenómeno de la paternidad social por el simple hecho de que un hombre decida ocupar ese lugar.

\section{Gravidez}

La gravidez se asocia a la suspensión de la menstruación genéricamente, no mediante un cómputo exacto de faltas. Para el indígena el embrión impide las pérdidas, de modo que la sangre se acumula en el vientre materno y fluye recién después del parto, lo que explica la duración de este período. El oscurecimiento de la aureola de los pezones y la avidez reiterada de comer ciertas vituallas son también síntomas de embarazo.

Los pilagá y los toba pueden recurrir al shamán a fin de que colabore con ellos en la elección del sexo del vástago. Para ello, aquél debe comunicarse con sus auxiliares y solicitarles que accedan a los anhelos de los progenitores.

$\mathrm{Al}$ asumirse el estado, o sea cuando es claramente perceptible, se operan cambios en la pareja. Desaparece el elemento erótico y se suspenden las relaciones sexuales -los mataco piensan que de mantenerse gestaría otro ser-: el marido satisface a su esposa en los más mínimos y triviales pedidos, en una atmósfera dominada por el cuidado constante y la demostración de ternura.
Si bien en los primeros meses la mujer no altera su rutina, va diariamente al bosque a recolectar, acarrea agua y leña y confecciona ceramios y textiles, con el correr del tiempo va disminuyendo su labor, hasta que la interrumpe completamente al acercarse el alumbramiento.

En el último período se respetan severas observancias alimenticias, especialmente las carnes, provengan de la caza o de la pesca, en virtud de que su consumo redundaría en perjuicios para el niño. Se prohiben -por ejemploel pato, la corzuela, el pecarí, el avestruz, los peces, los armadillos, el conejo, la iguana, el loro, etc.. El sentido de tal actitud apunta a evitar la identificación tanto física como caracteriologica entre el hijo y el animal ingerido. (Idoyaga Molina, 1976/77 y 78/79).

El hombre tampoco debe participar de las actividades cinegéticas, dado que de hacerlo su propia prole presentaría en su anatomía una marca similar a la realizada por el proyectil en el animal, y si aquel diera en la cabeza causaría su muerte.

De lo expuesto se deduce que, ante la inminencia del parto, se dejan de hacer todas las tareas que competen a los adultos; los esposos se recluyen prácticamente en su vivienda, y son asistidos por los restantes miembros de la familia.

El tratamiento singular que recibe la mujer y las prescripciones descritas traslucen que el embarazo implica el afianzamiento del aspecto comunitario, que cristaliza con la formación de la familia.

\section{Alumbramiento}

La proximidad del parto se hace evidente por las contracciones uterin -de acuerdo con los nativos, los movimientos bruscos del feto muestran sus deseos de nacer-y por la pérdida del líquido amniótico.

En el momento de dar a luz la joven es atendida en su choza por varias ancianas que ofician de comadronas, las que se encargan de masajear la zona abdominal de la puérpera; de recibir al bebé -evitando que toque el suelolavarlo y arroparlo; cortar el cordón umbilical; extraer la placenta y enterrarla en un rincón de la casa.

La razón de las prácticas reposa en la severidad del parto, dada por la intención nefasta de 
las teofanías que tratarán de dañar a la madre y al niño. Es esta peligrosidad la que exige la reclusión en la propia morada y la asistencia de ancianas, por ser éstas reservorio de un poder especial, adquirido durante el decurso vital, que les permite desenvolverse eficazmente (Idoyaga Molina, 1976/77 y 78/79).

En el caso de los pilagá, la mujer yace en el suelo -las mataco suelen hacerlo de cuclillas- y es aislada del ambiente mediante sendas mantas, que la envuelven completamente, para culminar su encierro. Las ancianas cantan y danzan en su derredor, convocando así a sus auxiliares. Se crea a su torno, de este modo, un campo calificado que impide que penetren los personajes míticos y facilita el normal desarrollo del trance (Idoyaga Molina, 1976/77).

Las acciones preventivas se extienden al baño purificatorio -a que se someten la puérpera y las participantes- y a la asperción de la habitación que tiene por objeto borrar restos de sangre o de su olor (Idoyaga Molina, 1976/77).

En los días siguientes no puede acercarse a los ámbitos acuáticos y debe respetar los mismo tabúes alimenticios que señalamos en relación con la menarca. Entre los toba y pilagá se cree que si la mujer menstruante consumiera carne, se convertiría en antropófaga, repitiendo un modelo mítico que explica el origen del canibalismo como estado.s

El peligro se va desvaneciendo con el pasar del tiempo; poco a poco la madre se reintegra a las tareas habituales, hasta que el desafio del alumbramiento queda atrás.

\section{Aborto}

El aborto es necesariamente resultado de una intención de la progenitora que, por uno u otro motivo, no quiere convertirse en madre, o de las deidades que por pura malignidad dañan a la mujer. Dicho de otro modo, no existe en la conciencia de los aborígenes la idea de un aborto inintencional, espontáneo, como tampoco existen razones sólo fisiológicas.

Los métodos tradicionales resultan a veces impresionantes; se espera que el embarazo esté adelantado, para dar una idea concreta, digamos entre seis y ocho meses. En tal ocasión las ancianas especialistas consuman el feticidio mediante golpes violentos al vientre materno, o localizando la cabeza y presionándola hasta quebrarla. La muerte del ser en gestación es instantánea, ya sea por asfixia, destrucción de órganos y tejidos, o detención de la circulación. Al actuar el feto, posteriormente, como cuerpo extraño, se provoca la contracción uterina, al principio localizada, hasta que alcanza el nivel de uniformidad suficiente como para expulsarlo. Los aborígenes suman a la explicación biológica de la muerte, otra de orden mítico-religioso en la medida en que la agresión física produce la huida del principio anímico, como dijimos el fundamento de vida (Idoyaga Molina, 1978/79 y 82).

En el momento del nacimiento, una anciana recibe el cuerpo evitando que toque el suelo, y enseguida lo entierra junto con el cordón umbilical, la placenta y la manta sobre la que yaciera la joven, en un costado de la choza. En esta oportunidad se iteran los comportamientos adoptados en el alumbramiento, tanto en lo que hace al ocultamiento, como a las prescripciones alimenticias y de resguardo en la propia vivienda. Es que en la visión nativa son acontecimientos asimilables y es por ello que se cumplen las mismas observancias. El riesgo está dado siempre por la presencia de las figuras míticas que procuran perjudicar irremediablemente a la joven (Idoyaga Molina, 1978/79 y 82). Entre los pilagá, a la gravedad ya apuntada se suma la amenaza del ser que se origina a partir del feto asesinado, un muerto terrible, que desea vengarse lesionando a la madre (Idoyaga Molina, 1982).

Entre los motivos que llevan al aborto se han señalado la soltería, el abandono del cónyuge, el adulterio y aun la represalia después de una querella con el esposo (Pelleschi, 1896, Metraux, 1937, 44, 46b, Arnott, 1935, Karsten, 1923). En rigor, lo que los autores tradicionales no han notado es que la categorización en mujeres solteras, abandonadas, adúlteras, o que mantienen relaciones conflictivas e inestables, puede tener algún valor para el occidental pero carece de asidero en las sociedades que nos ocupan, en las que los jóvenes se hallan sumidos en un particular estado emotivo que en el caso de la mujer comporta un continuo sucederse de esas circunstancias, las que aluden a un fenómeno más profundo y unitario, la calidad de Kyustislí (mataco), sanamañi (pilagá) e idagáyk (toba). Dichas 
voces pueden traducirse como enamoradizo y refieren una situación de desequilibrio afectivo, de uniones pasajeras y dominadas por la apetencia sexual, una conducta orientada a seducir constantemente, que es por otra parte, expresión del poder de los personajes míticos en el sujeto, los que los compelen a fascinar una y otra vez a las personas codiciadas. Para lograr el éxito, el individuo pinta su rostro con diferentes diseños en blanco, negro y rojo, se adorna con abultados collares y esmerados tocados, ejecuta ciertos instrumentos musicales, entona determinadas melodías y concurre a los bailes nocturnos en los que impera un ambiente orgiástico y se forman ocasionales parejas que culminan la velada entregados al juego amoroso. Los toba y pilagá construyen además, unos paquetes de magia hechizante envoltorios con rizomas montaraces y partes de aves canoras- cuya eficacia se trasunta en el aumento de la capacidad erotizante. ${ }^{6}$

Entre los mataco el ser kyustislí es resultado de la posesión que padece el humano por parte de los seres míticos, los que anulan su voluntad, convirtiéndolo en continente despersonalizado de su intención. Entre los toba y pilagá el nexo es distinto, el personaje es adquirido como auxiliar y colabora con su protegido en una comunidad de intenciones e intereses (Idoyaga Molina, 1976, 78, 81, Idoyaga Molina y Wright, 1984 y de los Ríos, 1978/79). De lo expuesto, se deduce que recurren al aborto las jóvenes en función de encontrarse en un estado peculiar, suscitado por la vinculación con las teofanías, las que determinan, orientan y alteran su comportamiento.

En los últimos tiempos se introdujo el uso de abortivos y anticonceptivos por influencia de los criollos. Al respecto cabe acotar que, considerando las nociones etnofisiológicas respecto de la concepción, la distinción mencionada no tiene valor para los indígenas. La utilización de unos y otros se funda en la eficiencia de los vegetales, los que al incorporarse al patrimonio, exigen técnicas de extracción y métodos de preparación en consonancia con el sistema cosmovisional.

\section{Infanticidio}

Dos tipos de hechos conducen al infanticidio: la condición de "enamoradizos" de los padres y el alumbramiento de mellizos y deformes. La primera ya la hemos explicado con relación al aborto, sólo podemos agregar que por ser el nexo entre padre e hijo entendido como dueño-dependiente, la falta de padre y por ende el vínculo necesario, lleva al infanticidio, puesto que un ser sin dueño es un ser sin sentido, sin ubicación en la sociedad y el mundo, un ser que no podrá ser alimentado, socializado, etc. Es decir, una realidad impensable.

La muerte de mellizos y deformes es un hecho generalizado en los tres grupos, sin embargo las razones que lo originan sólo se han relevado entre los pilagá y los toba occidentales (Idoyaga Molina, 1982, y Karsten, 1932). La creencia de que un hombre puede gestar un vástago por vez establece que la gemelidad, una segunda fecundación, es obra de las teofanías payák, peyák para Karsten, lo ontológicamente otro y potencialmente demoníaco (Sobre payák ver Idoyaga Molina, 1985). Por ser hijo de un payák el segundo en nacer, tiene su misma naturaleza, no es un ser humano y por lo tanto debe ser eliminado. Los deformes son igualmente, gestados por los payák, como lo revela inmediatamente su anatomía anómala. En efecto, los toba y pilagá piensan que todo ser que sea morfológicamente extraño no es un hombre, puesto que el plano de lo físico connota la alteridad existenciaria. De modo que también son ultimados en virtud de su esencia payák (Idoyaga Molina, 1982).

Para concretarlo el recién nacido es abandonado a su suerte en el bosque o asesinado por un anciano. El cadáver se sepulta en las cercanías de la vivienda sin ningún tipo de ajuar. Se inicia así un período especialmente tremendo para la madre y, de haberlo, para el gemelo con vida. El ser payák que se ha formado a partir de las entidades del vástago muerto no cesará su intento de vengarse. Entre los pilagá es común que la familia abandone la morada para trasladarse a un hogar seguro. Al shamán le corresponde restituir la bondad ambiental de la choza -ahora merodeada por un ser terrible-y proteger a la mujer de las acechanzas nocturnas de su hijo. Para lograr su cometido se dirige a la vivienda deshabitada cada atardecer y dialoga con el muerto hasta convencerlo de que desista de su actitud y parta hacia el 
mundo subterráneo, donde viven los difuntos. La práctica finaliza con un lavado purificatorio del sitio y el regreso de los afectados a la choza.

Es evidente que el infanticidio patentiza una de las circunstancias más angustiosas de la vida indígena, durante un tiempo el individuo se debate con los mal intencionados payák, que intentan darle muerte, y hacen de la propia casa un ámbito negativo que contagia todo lo que alli se encuentre. Es por eso que las acciones realizadas son de claro matiz preventivo o purificatorio.

Para finalizar, digamos que creemos haber mostrado la importancia que tiene la elicitación de la perspectiva nativa y la ubicación de los hechos en el sistema de representaciones, para alcanzar una efectiva comprensión de los mismos en cuanto realidad vivida.

\section{Notas}

1. Los temas que nos ocupan no han sido abordados sistemáticamente por los autores que se han ocupado de estos grupos, aparecen datos aquí y allá, sobre diversos aspectos y son especialmente escasas las referencias al plano del significado (Ver Pelleschi, 1896, Arnott, 1935, Karsten, 1923 y 32, Metraux, 1937, 44, 46, 46b y 73, Palavecino, 1933, 36 y 44). Un tratamiento más pormenorizado encontrados en de los Ríos (1974) y particularmente en nuestra propia contribución (Idoyaga Molina, $1976,1976 / 77$ y 1982). En la grafia de las voces aborígenes hemos seguido, para los matataco, la tabla de equivalencias propuestas por Califano y Braunstein (Califano, 1974). En lo que hace a los toba y pilagá es necesario hacer las siguientes aclaraciones, g) oclusiva velar sonora, k) oclusiva velar sorda, q) oclusiva uvular sorda, G) faríngea fricativa, ') oclusión glotal, y) semiconsonante o semivocal alveolopalatal no abocinada, w) semiconsonante o semivocal abocinada. Salvo estas consideraciones la transcripción está adaptada al castellano.

2. Un análisis del mito, en su versión pilagá, puede verse en Idoyaga Molina, 1988.

3. Un estudio de la versión mataco puede verse en Califano, 1973, y de la pilagá en Idoyaga Molina, 1987.

4. Sobre el nexo dueño-dependiente en la organización de la sociedad y la cosmología mataco véase Braunstein, 1974, y en lo relativo a los pilagá, Idoyaga Molina, 1989.

5. De acuerdo con un relato mítico, en el tiempo primordial una mujer violó la norma que impide el consumo de carne cuando se está con regla, fue así que inmediatamente comenzó a ingerir carne cruda y mas tarde cometió antropofagia. Su comportamiento inadmisible y peligroso determinó que los hombres llamaran a Qaqadelácbigi (versión pilagá) - Tanki (versión toba), un héroe salvador, quien mediante un ardid logró eliminarla. Su cadáver fue incinerado y a los pocos días de sus cenizas creció la planta del tabaco. En la actualidad cualquier mujer que no observe las prescripciones alimenticias, seguirá el mismo camino, convirtiéndose en antropófaga, estado al que también se puede acceder por la posesión de la figura originaria. Un análisis del mito entre los pilagá puede verse en Idoyaga Molina, 1985a.

6. Sobre sexualidad y pasión amorosa puede verse Idoyaga Molina, 1976, 78, 81, 87b, de los Ríos, 1978/79, Fock, 1963, Arenas y Braustein, 1981.

\section{Bibliografia}

Arenas, P. y Braunstein, J. 1981. "Plantas y animales empleados en paquetes y otras formas de la magia amorosa entre los TobaTaksik". Parodiana, 1(1).

Arnott, J. 1935. "La vida amorosa y conyugal de los indios del Gran Chaco". Revista Geográfica Americana. Vol. IV.

Braunstein, J. 1974. "Dominios y jerarquías en la cosmovisión de los mataco Tewok-sleléy". Scripta Etbnologica. Vol. II, parte 2.

Califano, M. 1973. "El ciclo de Tokwáj. Análisis fenomenológico de una narración mítica de los mataco costaneros". Scripta Ethnologica. Vol. I.

1974. "El concepto de enfermedad y muerte entre los mataco costaneros". Scripta Ethnologica. Vol. II, parte 2.

Fock, N. 1963. "Mataco Marriage." Folk. Vol. V.

Idoyaga Molina, A. 1976. "Matrimonio y pasión amorosa entre los mataco". Scripta Ethnológica. Vol. IV, parte 1.

1976/77. "Aproximación hermenéutica a las nociones de concepción, gravidez y alumbramiento entre los pilagá del Chaco Central". Scripta Ethnologica. Vol. IV, parte 2 . 
1978. La expresión de lo erótico en la cultura pilagá. En prensa CAEA Editorial.

1978/79. "Contribución al estudio del proceso de gestación, aborto y alumbramiento entre los mataco costaneros". Scripta Ethnologica. Vol. V, parte 2.

1981. "Sexualidad Pilagá". Publicaciones. Vol. XXXVII. Instituto de Antropología, Universidad Nacional de Córdoba.

1982. "Notas para el estudio de las prácticas de aborto e infanticidio entre los pilagá". Acta psiquiátrica y psicológica de América Latina. Vol. XXVIII, No.3.

1985a. "The myth of NesóGe. A hermeneutic analysis of a Pilagá relation." Latin American Indian Literature Journal. Vol. 1. No.1.

1985b. "El payák. Una estructura mítico-religiosa del mundo pilagá". Zeitschrift für Ethonologie. Tomo 110, No.2.

1987a. "Estudio fenomenológico del mito de origen de las mujeres entre los Pilagá. (Chaco Central)". Presentado al V International Symposium on Latin American Indian Literature. Ithaca (USA), junio de 1987.

1987b. "Sexualidad y erotismo entre los jóvenes mataco". En prensa en Revista de la Sociedad Cientifica Angentina.

1988. "Aproximación al mito de la mujer menstruante y el cataclismo acuático entre los pilagá. (Chaco Central)". Presentado al VI International Symposium on Latin American Indian Literature. Guatemala, junio de 1988.

1989. Modos de clasificación de la realidad en la cultura pilagá. CAEA Editorial.

Idoyaga Molina, A. y Wright, P. 1984. Introducción sociocultural, cosmovisional $y$ lingüística a los grupos aborigenes de la Provincia de Formosa. Ministerio de Educación de la Provincia de Formosa.
Karsten, R. 1923. "The toba indians of the Bolivian Gran Chaco." Acta Academiae Aboensis Humaniora. Vol. IV.

1932. "Indians Tribes of the Argentine and Bolivian Chaco." Commentationes Humanarum Literarum, Societas Scientiarum Fennica. Vol. IV.

Metraux, A. 1937. "Etudes d'Ethonographie TobaPilagá (Gran Chaco)". Antbropos. Vol. XXXII.

1944. Nota etnográfica sobre los

- indios Mataco del Gran Chaco Argentino. Relaciones, de la sociedad Argentina de Antropología. Vol. IV.

1946a. "Myths of the Toba and Pilagá Indians." Memoirs of the American Folk Lore Society. XI.

1946b. "Ethnography of the Chaco" Hand-book of South American Indian. Vol. 1.

1973. "Conversaciones con Pedro y Kedoc". En Religion y Magias Indígenas de América del Sur. Ed. Aguilar, Madrid.

Palavecino, E. 1933. "Los indios Pilagá del Río Pilcomayo". Anales del Museo Nacional de Historia Natural. XXXVII.

1936. "Las Culturas Aborígenes del Chaco". En Historia de la Nación Argentina. T.I.

1944. "Prácticas funerarias norteñas". Relaciones, de la Sociedad Argentina de Antropología. Vol. IV.

Pelleschi, G. "Los indios matacos y su lengua". Boletín del Instituto Geográfico Argentino. Vol. XVII.

Ríos, M. de los. "Vida y muerte en el cosmos mataco". Cuadernos Franciscanos, No.35.

.1978/79. "Las expresiones de la afección amorosa en la etnia Mataco". Scripta Ethnologica, Vol. V., parte 1. 
